\title{
Disrupting the Past to Disrupt the Future: An Antenarrative of Technical Communication
}

\author{
Natasha N. Jones ${ }^{a}$, Kristen R. Moore ${ }^{b}$, and Rebecca Walton ${ }^{c}$ \\ aUniversity of Central Florida; ${ }^{\mathrm{b} T e x a s}$ Tech University; 'Utah State University
}

\begin{abstract}
This article presents an antenarrative of the field of technical and professional communication. Part methodology and part practice, an antenarrative allows the work of the field to be reseen, forges new paths forward, and emboldens the field's objectives to unabashedly embrace social justice and inclusivity as part of its core narrative. The authors present a heuristic that can usefully extend the pursuit of inclusivity in technical and professional communication.
\end{abstract}

\section{KEYWORDS}

History of technical communication; inclusion; methodology; social justice

\section{Introduction}

At the colocated CPTSC and SIGDOC conferences in 2014, panels at both conferences interrogated the role of social justice and ethics in technical communication. These panels represent a necessary turn in the field of technical communication: moving from mere ethics, which often exist in an individual's character or behavior, to a social justice stance, which tends to be more collective and action oriented. The panels reflected Rude's (2009) depiction of technical and professional communication (TPC) as "a field of study and practice that contributes not just to self-perpetuation and best practices in its own area but also to the good of society" (p. 201). But Rude noted that this approach requires reflexivity to be done well. In noting the field's nascent turn toward social justice, we reflect on and celebrate the work that could be categorized within Rude's (2009) "social action" category of TPC scholarship, though considerations of inclusion and diversity in technical communication research and pedagogy remain sparse. Or so it may seem.

Indeed, when we look beyond grand narratives and draw together work addressing "the good of society" from a variety of perspectives, we see that scholars across the field have begun to do the difficult work of carving out a space for scholarship that attends to social justice and improving the diversity of our academic community. For example, the 2012 CPTSC keynote by Miriam F. Williams (2013), acknowledged the work of TPC scholars who explicitly mitigate marginalization:

These scholars are taking the traditional description of technical communication as a field that advocates for the user to a new and exciting level by focusing on historically marginalized groups and issues related to race,

class, gender, and sexuality because these identity factors are not mutually exclusive. (pp. 87-88)

The work of TPC scholars to address inclusion, social justice, and diversity tempers claims of an "apolitical and acultural" area of study and presents a "counterargument" to these criticisms (Williams, 2013, p. 88).

Although TPC scholars have long been exploring issues of inclusion, the collective contribution of this work has gone largely unnoticed, (over)shadowed by the dominant narrative that technical communication is most concerned with objective, apolitical, acultural practices, theories, and pedagogies. The official narrative of our field indicates that TPC is about practical problem solving: 
a pragmatic identity that values effectiveness. But this is not the whole story. The narrative should be reframed to make visible competing (i.e., a collection of nondominant) narratives about the work our field can and should do. What is needed, we argue, is an antenarrative. Part methodology and part practice, an antenarrative allows the work of the field to be reseen, forges new paths forward, and emboldens the field's objectives to unabashedly embrace social justice and inclusivity as part of its core (rather than marginal or optional) narrative. We argue that the field needs a more focused study of the ways inclusivity has emerged in the field and the strategies/approaches that can usefully extend the pursuit of inclusivity. As such, several research questions motivate this study:

(1) What common threads emerge under the broad umbrella of inclusivity?

(2) How might these threads, when drawn together, help us move forward in pursuit of inclusion as a central tenet of TPC?

(3) If we accept that inclusivity is an integral part of our field's history, how can or should we proceed?

We answer these questions through an antenarrative of the field's history: a disruptive "before" story that seeks to destabilize and unravel aspects of the tightly woven dominant narrative about who we are as a field, what we do, where our work occurs, and what we value. David Boje (2001) introduced the term antenarrative to describe "fragmented, non-linear, incoherent, collective, unplotted, and improper storytelling" (p. 1). In contrast to narratives, which Boje (2011) conceived as characterized by "stability and order and univocality" (p. 5), antenarratives are poly-vocal, dynamic, and fragmented-yet highly interconnected. They link the static dominant narrative of the past with the dynamic "lived story" of the present to enable reflective (past oriented) and prospective (future oriented) sense making (Boje, 2008, pp. 6, 13). It is in this sense making where much of antenarratives' value lies because antenarratives are vital to the working out of actionable knowledge (Boje, Rosile, \& Gardner, 2004, p. 1). They can enable change:

These fragile antenarratives, like the butterfly, are sometimes able to change the future, to set changes and transformations in motion that have impact on the big picture. More accurately, antenarratives seem to bring about a future that would not otherwise be. (Boje, 2008, pp. 13-14)

Antenarratives open up a space that invites reinterpretation of the past so as to suggest-and enable-different possibilities for the future.

The antenarrative presented in this article looks to the future by examining the past. We assert that specific, pragmatic actions are necessary to create effective change going forward. To that end, in addition to reflecting on work that has been done and pointing to future opportunities for more inclusive TPC work, we also present a framework for developing a more inclusive focus in TPC research. This framework addresses inclusion by interrogating how social and ideological identity markers (like race, gender, sexuality, and ableness) are coconstructed and shaped by what we call the 3Ps: positionality, privilege, and power. These 3Ps function as macrolevel concepts that can affect social capital and agency. In regard to TPC, an awareness of how the 3Ps are articulated and inscribed in our work is a necessary step toward increasing the inclusivity of our research and practice.

In the spirit of full disclosure, we write this article because it is the article we need when we write about our own inclusive work. When Jones writes about the Innocence Project, or Moore writes about public engagement in public planning projects, or Walton writes about field research in the Global South, each needs a foundational piece to point to that commits to the field a view of technical communication and its inclusive efforts. The struggle to justify our work as TPC scholarship derails our arguments, causes unnecessary throat clearing, and is just plain frustrating. We see scholars across the field who are committed to broadening opportunities for citizens, users, scholars, students, and participants. But the dominant narratives of efficiency, technological expertise, and innovative infrastructure too often dominate the field and research projects where inclusion sits at 
the heart of the project. To be clear: an antenarrative is NOT a literature review that synthesizes a cohesive corpus of work. Antenarrative points to disjointed portions of a story that is still struggling to be told. Boje (2001) noted that "rather than reified plots, there are fragments of stories, bits and pieces told here and there, to varying audiences, so that no one knows a whole story ... And pockets of some agreement come undone" (p. 5). We assert not just that these stories of inclusivity and social justice need to be told, but that telling them in the same place, with multiple voices renews the otherwise silenced stories and invites others to join it.

In this article, we first interrogate the dominant narrative that weaves an orderly, completed tapestry of the field and then present a collection of nondominant stories, an antenarrative: threads with the power to unravel aspects of the field's tidy tapestry. Third, we articulate a vision for inclusive technical communication and suggest reasons why inclusive approaches to technical communication ought to be adopted. Finally, we present a heuristic for addressing inclusion in TPC research using the 3 Ps.

\section{Interrogating the dominant narrative}

The field's historical, dominant narrative can be seen in early descriptions of successful TPC, such as effectiveness as a sole criterion for "good" technical writing-one of two major conclusions of a 1940s survey of technical writers in industry (Connors, 1982). This survey informed the most popular technical writing textbook of the 1950s-thus perpetuating a pragmatic identity that has persisted to today: see, for example, Johnson-Eilola and Selber's (2013) description of their recent edited collection as helping readers "to think about technical communication as a problem-solving activity" (p. 3). Like other excellent and influential collections in our field (e.g., Zachry \& Thralls, 2007), the scope of this collection is bounded by the dominant narrative: for example, privileging pragmatic topics such as usability and information design with an eye to workplace problem solving. We, too, prefer our problems solved, but we do not believe the narrative of our field (our history, our purpose, our identity) can be-nor should it be-so neatly encompassed by a coherently pragmatic identity. This is one of the overarching benefits of an antenarrative approach: Antenarrative operates in conjunction with-that is, in conversation with but often in tension with-the already accepted and more cohesive dominant narrative.

Not all scholars in the field adopt or embrace this coherent pragmatic identity. Indeed, the antenarrative we present in this article rests upon widely accepted movements in the field, namely, humanism and the sociocultural turn, in which focus shifted from problem solving and efficiency to human impact. Advocating for the relevance of humanism to technical communication, Miller (1979) introduced the importance of seeing language beyond the limited frames of instrumental discourse. Her early work reinfused science with rhetoric and challenged the field to broaden its understanding of what technical communication can and should do. And others followed suit (Herndl, 1993; Katz, 1992; Sullivan, 1990). Although the primary practices and sites of technical communication remained entrenched in science, engineering, and technology studies, the field broadened its perspectives on the ways language and discourse press upon these practices (see Slack, Miller, \& Doak, 1993). As social constructivist approaches to discourse became central to the field of technical communication, questions of power, authorship, and ethics, among others, also emerged (for example, Barton \& Barton, 1993; Blyler, 1995; Johnson-Eilola, 1996; Ornatowski, 1992; Scott, 1995). Scholarship from the sociocultural turn drew attention to our field's complicity in oppression (Scott, Longo, \& Wills, 2006, p. 1) by identifying and analyzing field-relevant examples of marginalization (Palmeri, 2006; Salvo, 2001) and cultural imperialism (Hunsinger, 2006).

These movements are necessary preconditions for the antenarrative threads we present in the disruptive history that follows: exposing the need for and the history of a more inclusive technical communication that we might be better positioned to pursue inclusivity as a central goal. By inclusive, we refer to efforts to forward a more expansive vision of TPC, one that intentionally seeks marginalized perspectives, privileges these perspectives, and promotes them through action. 
In short, the only stories that are heard are the stories that are (re)told. Thus, we engage an antenarrative methodology, which unravels and reweaves threads of our field's (his)story to open up new possibilities for the future stories we tell and enact. The following section reviews important, but not always visible, stories that progress an ideal of a more inclusive technical communication.

\section{Threads of TPC: An unravelling and reweaving}

This antenarrative traces threads of TPC history, foregrounding movements, voices, and disciplinary efforts that enable scholars to build a more inclusive technical communication. Rather than present a new origin story, a history, or an ordered overview of the inclusive threads, we offer fragments (think of threads of a larger tapestry) that together offer a way forward that reenvisions the field. These threads include scholarly work that typically functions at the margins: scholarship in feminism, sexuality, and gender studies; user advocacy; community-based research; intercultural and international studies; disability studies; and race and ethnicity studies. Historically, these threads have been addressed individually, each area of scholarship struggling to make evident its benefits for the field of technical communication, and some threads enjoy more acceptance and integration into the broader field than others. Rather than build an argument about the marginalization of particular areas, we instead weave a tapestry that draws these threads together, identifying their shared (though fragmentary) interest in expanding the scope of the field and thereby shifting its focus. This section functions to assemble and re-present existing threads not as a static or comprehensive narrative, but as a collective that forwards inclusivity and advocacy and disrupts the dominant narrative we overviewed in the previous section.

\section{Feminism and gender studies}

The first antenarrative thread represents some of the earliest moves to increase inclusivity in TPC by exploring gender and feminism. During the 1990s, the field experienced a surge in scholarly work addressing gender. This surge emerged mostly in the form of special issues in the Journal of Business and Technical Communication (on the cultural turn in 1991), IEEE Transactions on Professional Communication (on gendered assumptions of rationality in 1992), and Technical Communication Quarterly (on social understanding of gender in 1994 and recovered histories of women in technical communication in 1997). Throughout the decade, scholars (primarily female scholars) argued for a correction of history to eliminate the exclusion of women and women's work (Durack, 1997; Kynell, Tebeaux, \& Allen, 1997) and an awareness of how gender colors our assumptions about rationality, knowledge making, and research (Smith \& Thompson, 2002; Thompson, 2004). Scholars invested in feminist theory and methodology highlight its promise for informing and improving the field (Bosley, 1994; Gurak \& Bayer, 2004; Koerber, 2000; Lay, 1991; Sauer, 1993). LaDuc and Goldrick-Jones (1994), for example, summarized a key contribution of feminist work: "looking through the lens of gender allows the writer-scholar-teacher to see how a number of communication practices can be oppressive" (p. 247).

These special issues are indicative of (1) the fact that a number of scholars across the field were introducing new ways to include women and issues of gender into the field of TPC and also (2) the ways in which this effort was somewhat quarantined from mainstream discussions. Indeed, we see gender and feminism as an important antenarrative thread in part because it seems to repeatedly emerge only to be covered over again without having its due impact on the overall pattern of the tapestry (i.e., the field). Indeed, in their attempt to catalog women/gender/sex in the fields' five journals, Thompson and Smith (2006) reported only 21 articles published between 1994 (the height of the special issue surge) and 2004, and significant gaps remain. Since the turn of the century, for example, TPC scholars have offered gender, explicitly, limited attention (with some notable exceptions such as Brasseur, 2005; Lippincott, 2003; Zdenek, 2007). An additional concern is the limited feminist lens that largely furthers the White feminist cause, with little attention to the role of women of color and their experiences in the TPC field (Jones, 2016b; Moore, forthcoming). 
This dearth of feminist and gender scholarship points to the need for an antenarrative that makes visible the work that has been done and continues to be done. Further, an antenarrative perspective affords researchers the opportunity to "put the fragments together," acknowledging the gaps in continuity and content in feminist and gendered approaches to TPC research (Boje, 2001, p. 9). For instance, Koerber sustains a feminist agenda throughout her work both in technology (2000) and in medical rhetoric (2013). Extending the work of Durack (1997), Koerber (2013) located new sites of technical communication in breastfeeding discourse. Britt (2001), too, extended the purview of feminist technical communication by introducing reproductive technologies (and public policy) as a part of the field. Frost (2015) troubled the fragmented treatment of gender and feminism within the field, arguing for an "apparent feminism" that highlights feminisms' and feminists' potential for making political change. In addition, there is burgeoning interest in and efforts to mentor women for positions of leadership (e.g., the introduction of the Women in Tech Comm organization in 2013, publications such as Sullivan \& Moore, 2013, and the widespread leadership of women in the field's professional organizations such as ATTW and SIGDOC).

\section{Race and ethnicity}

Recently, TPC scholarship has worked toward inclusion through research that addresses racial and ethnic diversity, but focused and sustained critical engagement has been sparse and fragmented. Antenarrative is useful for drawing attention to the contributions and significance of this sparse, fragmented collection of work. The antenarrative approach of microstoria analysis specifically focuses on the narratives of minorities (racial and ethnic minorities, as well as gendered minorities, minority groups of socioeconomic class, and other types of minorities), providing a space for scholars to call out ruptures in the dominant narrative (Boje, 2001, p. 45). This antenarrative points to these disruptions. Relatively few TPC scholars explicitly mention race and ethnicity, instead using the more general term diversity. This diversity focus has, at times, served as an insufficient stand-in for addressing race and ethnicity. For instance, the 1994 special issue of Journal of Business and Technical Communication on communication, the workplace, and "diversity of all kinds, including race, gender, and ethnicity" (Limaye, 1994, p. 277) primarily included articles that only tangentially acknowledged issues of race and instead relied heavily on broader discussions of diversity.

A notable exception is Kossek and Zonia's (1994) piece, which examined how racial and ethnic groups (including Asians, Hispanics, and African Americans) responded to employer attempts to increase diversity in the workplace. This interest in racial diversity has been taken up more recently by Savage and Mattson (2011), who moved the conversation forward by establishing "a baseline of information about diversity in technical communication programs" (p. 42). These scholars called for further devotion to the field's diversification in terms of under-represented populations and the cultural perspectives that inform our scholarship and pedagogy.

The move toward naming race and ethnicity (rather than diversity in general) as viable and important in technical communication research and pedagogy has been slow going, with only a few examples to draw on (see Banks, 2006; Blackmon, 2004; Haas, 2012; Williams, 2010). A recent special issue of the Journal of Business and Technical Communication (JBTC) extended the discussion with an exclusive focus on race and ethnicity. Special issue editors Williams and Pimentel (2012) acknowledged that part of the difficulty of garnering and sustaining scholarly conversations about race and ethnicity is that "many, inside and outside of our field, believe that race is not a relevant concept in our society or field. Some argue that we live in a nonracist society, and thus the need to acknowledge color no longer exists" (p. 272). The scholars in the JBTC special issue (Evia \& Patriarca, 2012; Haas, 2012; Pimentel \& Balzhiser, 2012) and their subsequent edited collection (Williams \& Pimentel, 2012) help pave the way for other scholars to "move beyond issues of diversity in the practice of technical communication" (p. 1). Doing so acknowledges the fact that the field's relative silence about how race and ethnicity affects the invention, practice, delivery, and engagement of technical communication can and has negatively affected groups that are marginalized and disenfranchised (p. 1). And, as we will later argue, the acknowledgment of harm done is vital for transitioning from mere diversity to true inclusivity. 
Although work explicitly engaging with race and ethnicity has been limited, important gains have been made. Scholars are recognizing that race and ethnicity is not only a rich area for research and pedagogy, but one that requires open conversations about how these sociopolitical identity markers manifest in our field. Weaving more visible threads of this work into the tapestry of our field requires more scholars contributing to the dialogue and a shift from general discussions of diversity to contextualized, targeted examinations of race and ethnicity. As the field continues to grow, emerging scholars are adding their voices to conversations about race in technical communication (e.g., Jones, 2014; Kelly, 2014; Medina, 2014; Richardson, 2014), a promising trend for those concerned with race and ethnicity in TPC.

\section{International/intercultural professional communication}

As we continue on with our antenarrative, highlighting and "tracing story fragments" (Boje, 2001, p. 5), we explore how the goal of crafting more inclusive TPC has underlain international and intercultural work in our field since we first began acknowledging culture as a relevant consideration. In fact, although the theories and methodologies of international/intercultural professional communication (IPC) vary widely, common justifications for one approach over another are the inclusivity and complexity enabled by one's selected approach (e.g., Hunsinger, 2006; Thatcher, 2010).

In the early 1990s, several influential works (Beamer, 1992; Victor, 1992) called for more research on international and intercultural contexts of TPC. In the decades following, IPC became a burgeoning subset of the field (Ding \& Savage, 2013). The most common theories informing this work in the 1990s and early 2000s were the comparative frameworks of Hall and Hofstede (Cardon, 2008). Although these theories are no longer ubiquitous in IPC, scholars defending comparative frameworks do so on the basis of equality and inclusivity. For example, in arguing for an etic-then-emic approach, Thatcher (2010) called IPC scholars to first identify shared behaviors or concerns (i.e., etic focus) and then investigate how specific groups of people address or enact these concerns (i.e., emic focus), thereby avoiding the ethnocentricity of one culture serving as a norm against which others are compared.

Interestingly, other IPC scholars reject comparative frameworks in pursuit of the same goal: more inclusive, equitable research. Influenced by critical theory, these scholars argued for a local focus that is attuned to differences in perspectives and that recognizes the legitimacy of these perspectives (Hunsinger, 2006; Sullivan \& Porter, 1998). Calling for a broader scope of intercultural/international inquiry beyond the linguistic and textual, scholars began looking to local knowledge systems, historical backgrounds, economic conditions, and other social and political factors (Agboka, 2013; Hunsinger, 2006). Other efforts to disrupt the conventionally limited conception of intercultural TPC include working to ameliorate the ways this term "blackboxes" the nuances of cultural difference (see Haas, 2012). In pursuit of this goal, some IPC scholars have connected technology use to cross-cultural communication, illustrating the ways that users in different contexts and cultures deploy technology (Sun, 2012; Walton, 2013a).

Recent perspectives on IPC reject any expectation of cultural "purity" and instead

- focus on the space between cultures (Matsuda \& Atkinson, 2008)

- involve conducting multilevel analyses considering nation, region, organization, and individual (Thatcher, 2006; Walton, 2013b)

- transcend national contexts to investigate global phenomena and transcultural communities (Ding, 2013; Starke-Meyerring, 2005).

This work resists oversimplified, static conceptions of culture as ethnocentric and dehumanizing: facilitating stereotyping and thus eliminating the complex, dynamic, multicultural experiences. The work of IPC scholars, regardless of particular methodologies or practices, has paved a way for other scholars to adopt ethical and inclusive TPC practices that expand beyond the realm of IPC. 


\section{Community and public engagement}

Scholars in TPC have invested in localized studies of community and public engagement, and these efforts, too, have driven the field toward more inclusive practices. In fact, technical communicators working in communities and the public sphere represent similar moves toward inclusivity. In locating technical communication within community sites and exploring the function of technical documents outside of corporate contexts, researchers present a broadly construed research agenda that often resists the technocratic approach that dominates decision-making in the public sphere (Waddell, 1996). Community-based technical communication, then, provides a foundation for expanding TPC audiences. Not merely users but active cocreators, citizens of all kinds require technical communication that demands more expansive, inclusive approaches to communication practices and to the theories that undergird knowledge making (Coppola \& Karis, 1999; Grabill \& Simmons, 1998; Paretti, 2001; Simmons, 2007). As seen in the antenarrative presented below, an ideal approach for pulling together multiple voices and multiple perspectives is to connect citizens' voices and stories to develop and inform technical communication practices and promote local sense-making.

Technical communicators have examined how environmental decisions can be made within specific, localized communities. Further, claims that citizens ought to be involved in decision making surrounding environmental discourse shifted perspectives about technical communication in the public sphere: more than analyzing the Environmental Impact Statement (EIS) as a technical document, for example, Waddell (1996) suggested that technical communicators have an ethical obligation to advocate for more inclusive and just processes. Indeed, this was Simmons' (2007) argument, as she constructed a heuristic for public decision making. Beyond environmental studies, technical communicators have argued for the development of community-based research in a variety of contexts: medical rhetoric (Scott, 2003), community literacy (Grabill, 2001), urban planning (Grabill, 2003; Moore \& Elliott, 2016), community websites (Simmons \& Grabill, 2007; Simmons \& Zoetewey, 2012), public policy and legislation (Hannah, 2010), and training/education (Dubinsky, 2004; Eble \& Gaillet, 2004). These community-based scholarly agendas have shaped not only research but also pedagogy: for example, service- and community-learning curricula. Many scholars agree that when students expand their audiences to include local communities, learning opportunities regarding ethics and diversity are also expanded (Scott, 2004). Pedagogical innovations in the community have provided curricular motivations for an inclusive technical communication, and the teacher-scholars who enact these pedagogies provide an impetus for expanding our theoretical and practical approaches to TPC.

Conceptualized as an inclusive approach, research and pedagogy that adopt community-based methods emphasize civic and social responsibility while enacting principles of collective action such as dialogue, reflection, and advocacy as means for improving and contributing to public life (Eble \& Gaillet, 2004). As Ornatowski and Bekins (2004) noted, this focus on civic and community engagement allows TPC scholars to focus on "broader democratic and human concerns in order to open up the field to civic advocacy and action and make it [the field of TPC] responsive to progressive political agendas focused on individual and collective empowerment and emancipation" (p. 252). In this way, community and public engagement has the potential to encourage scholars' considerations of social justice as a humanistic approach and affords scholars the opportunity to integrate social justice into research and pedagogy within the field (Jones, 2016b).

\section{User advocacy}

User advocacy is a prominent thread in the antenarrative of our field, informing our work from early definitions (Dobrin, 1983; Miller, 1979) to projections of future contributions (Redish, 2010; Sun, 2012). In defining our work as "writing that accommodates technology to the user," Dobrin (1983, p. 119) placed users' concerns at the center of the field, an early move that refigured the field to actively seek out and accommodate user perspectives. More than 30 years later, this definition has been contested for its exclusive focus on writing and technology but not for its user focus, a focus that has grown more complex 
as our attention to inclusion increases (Walton, 2016). Inclusive scholars who address issues of user advocacy pick apart the threads of the dominant narrative that weave a simple story by interrogating which users are being accommodated, represented, and considered-and which users are not. This antenarrative thread reweaves a more complex story of user advocacy in the field.

User advocacy is not fully enacted by merely making objects easy to use but also includes respecting users enough to convey effects of use so they can make informed decisions (Johnson, 1998). Because user advocacy is central to our work, it is correspondingly foundational to our methods: for example, using participatory design to enable a better understanding of users' tacit knowledge (Moore \& Elliott, 2016; Spinuzzi, 2005) and engaging in methods specifically suited to inclusive design, such as feminist-informed narrative inquiry (Jones, 2016a) and decolonial methodologies (Agboka, 2014).

User advocacy also drives our interdisciplinary influence, with TPC shaping usability and user experience (UX) since the 1970s through today (Redish, 2010; Redish \& Barnum, 2011; Sullivan, 1989). User advocacy is at the core of usability, UX, user-centered design, participatory design, humancentered design, and value-sensitive design (Friess, 2010, p. 42). But user advocacy is no simple matter. It is complex and difficult to decide whose experience, needs, and voice should be most influential in shaping our research, pedagogy, and practice, let alone how to go about facilitating that influence (Getto, 2014; Moore, 2013; Mukavetz, 2014; Simmons \& Zoetewey, 2012; Walton, 2013b). In addressing this challenge, many inclusive scholars intentionally shift power toward users, particularly those who are marginalized, creating space for marginalized users' expertise to be recognized as legitimate (e.g., Agboka, 2014; Dura, Singhal, \& Elias, 2013; Johnson, 1998; Jones, 2016a; Mukavetz, 2014; Price, Walton, \& Petersen, 2014; Walton, 2016).

\section{Disability and accessibility}

An important but less prominent thread of scholarship addresses disability and accessibility as a means of becoming more inclusive by resisting ableism. This work rejects assumptions of access that exclude particular students, users, and others from fully engaging with forms of technical communication. Indeed, disability scholars remind us that in focusing on efficiency and innovation, TPC has widely embraced an ableist agenda. The need for integrating disability rhetoric and accessibility into the field has only begun to be addressed, but as we craft an inclusive technical communication, disability, accessibility, and questions of normalcy illuminate ways forward. In shining light on this work, our antenarrative makes visible how this scholarship unravels bits of the field's efficiency-driven narrative.

Perhaps because accessibility so readily connects with user advocacy and user-centered design, more TPC scholars have addressed accessibility than disability (Palmeri, 2006). In the early 21st century as the web took hold, TPC scholars and practitioners began paying attention to web standards and the need for accessible sites (see, e.g., Carter \& Markel, 2001). More than just a series of structural steps, accessibility requires interpretation; it is a rhetorical enterprise (Spinuzzi, 2007). But, as Walters (2010) noted, TPC's investments in questions of disability "have tended to focus on specific disabilities or specific contexts" (p. 429). Yet scholars have argued that TPC requires more robust and expansive frameworks for understanding disability (Oswal \& Meloncon, 2014; Palmeri, 2006; Spinuzzi, 2007; Walters, 2010; Youngblood, 2013). For example, scholars pointed out our field's complicity in exclusion by revealing implicit messages of deviance and abnormality in medical models of disability, messages that are often uncritically accepted and reproduced in TPC (Gutsell \& Hulgin, 2013; Palmeri, 2006). Palmeri's work (2006) allows TPC scholars to reenvision technical communication through the lens of universal design and adapt "social discourses and material environments to ensure participation for citizens of diverse abilities” (p. 50). And because everyone's abilities fluctuate, everyone is and will be disabled in various ways, extents, and contexts (Jarrett, Redish, \& Summers, 2013; Pass, 2013).

Recent scholarship picks up Palmeri's initiative to address issues of disability and accessibility, promoting concrete practices to teach undergraduates (Pass, 2013; Youngblood, 2013) and 
instructors (Oswal \& Hewett, 2013) about the important legal and ethical ramifications of ableist approaches to design. Reporting a national survey about online writing instruction, Oswal and Meloncon (2014) encouraged scholars and teachers in TPC to "think about how power and privilege could impede accessibility and accommodation" (p. 273). As noted by Gutsell and Hulgin (2013), language plays a key role in constructing power and privilege, highlighting the importance of "understanding language and the representation of disabilities, and its connection to cultural meaning and the associated challenge to support inclusion through technical communication" (p. 84). Central to issues of disability and accessibility, the notion of ensuring participation is encapsulated in the inclusive technical communication antenarrative we weave here.

\section{Diversity, social justice, and inclusion}

Having trod out these threads, we risk telling stories some of our readers have already heard and accepted. But, we argue, not telling these stories comes with a far greater risk: to allow important work in our field to remain marginal and dormant. Applying the antenarrative methodology, we have conveyed the fragmentary nature of inclusive TPC scholarship and brought to the fore extant work but have also highlighted the incohesive and inconsistent production and analysis of this scholarship. Our goal is not to create a seamless tracing of the literature (which would defeat the purpose of an antenarrative). However, we do seek to emphasize the need for and the opportunities to perceive the scholarship in TPC from a different, and more reflective perspective. This section seizes the antenarrative we laid out as an instrument of change and uses it to launch a heuristic that helps the field extend more fully the disciplinary pursuit of inclusion. Ultimately, inclusion, what we argue for in this text, is an ideal that we believe the field of TPC should work toward. Inclusion means that there is respect for everyone's voices, stories, and knowledges. Diversity, which addresses representation in its most basic form, is a necessary precondition of inclusion: We have to get everyone to the table to be able to do the messy work of promoting and enacting social justice to create a more inclusive environment.

The antenarrative threads that we have presented in this text collectively invite reinterpretation of the past and allow us to make these movements visible-movements in which scholars have engaged to create diversity (the first step toward inclusion). In addition to improving diversity in TPC, these threads simultaneously include some social justice work. Moving past critical reflection, "social justice research in technical communication investigates how communication broadly defined can amplify the agency of oppressed people-those who are materially, socially, politically, and/or economically under-resourced" (Jones \& Walton, forthcoming). Social justice extends diversity work by focusing on action; this action, we argue, can lead to inclusion.

Because diversity is concerned primarily with representation and heavily relies upon reflection, diversity alone does not ensure inclusion (Cushman, 2015). Social justice, which is concerned with action, is a priority once-marginalized groups are represented and then invited into critical dialogue. Refusing to ignore or smooth over injustices in the name of moving forward, social justice involves redressing inequities and acknowledging harm (Jones \& Walton, forthcoming). Thus, social justice is the bridge from diversity to inclusion. Inclusion is our ideal, desired future. To open possibilities for that desired future, we have used antenarrative to present threads of past work, making more visible these attempts to improve diversity and to enact social justice. Clearly, more social justice work must to be done before our field can be considered inclusive. However, antenarrative makes evident the possibilities for our future by affording a method for making sense of our past. This future-oriented sense making is necessary for scholars in the field to move beyond diversity, through social justice, toward inclusive research and pedagogy in TPC. This is the promise of antenarrative. 
In disrupting the dominant narrative of our field and presenting a different view of our history, the antenarrative we weave in this article opens space for a number of affordances, implications, and strategies that enable and demand a more inclusive field. ${ }^{1}$ In this final section, we offer a heuristic approach to moving forward in the spirit of the antenarrative. Our focus on the goal of inclusion allows scholars to examine macrolevel concepts that can impact social capital and agency. We term these macrolevel concepts the 3Ps: positionality, privilege, and power. The 3Ps inarguably affect and coconstruct the ways in which people engage with identity markers such as race, ethnicity, gender, sexuality, ableness, religion, and class. Below we briefly define each of the 3Ps and then demonstrate their value as a heuristic for inclusive TPC. This heuristic scaffolds researchers in (1) thinking more critically about how certain groups are marginalized and disempowered and in (2) recognizing specific ways that our research can either reinscribe marginalization and disempowerment or promote agency and advocacy.

\section{Positionality}

Introduced by scholars such as Alcoff (1988), positionality is the idea that aspects of identity-such as race and gender-are not essential qualities but are identity markers that are

- relational-that is, are meaningful when considered in relation to other information. (It may be more meaningful to consider what it means to "be a man," for example, when considered alongside what it means to "be a woman" or when considered within a particular context of manhood.)

- historical-that is, must be understood in the context of historical social situations that created these constructs and continue to shape their meaning.

- dynamic and particular - that is, what it means to "be a woman" or to "be able bodied" varies based on one's situation-culture, historical time period, other identity markers, time and phase of life, and so on. (This is one reason why it is so difficult-and potentially marginalizing - to define identity markers in a universal way.)

\section{Privilege}

Stemming from preferred positionality (such as being able bodied or being White), privilege is an unearned advantage that benefits those who are granted this status to the exclusion and detriment of those who are not (Black \& Stone, 2005, p. 244). We might think of privilege as positionality that aligns with society's default assumptions, and, of course, these assumptions vary based on who "society" is. People occupy varying positions and degrees of privilege based, in large part, on sociopolitical constructs like gender, sexuality, ableness, and so on, as well as other factors such as body size, for example. The complexity of privilege has important implications, such as the need to acknowledge similarities and differences in the ways that specific privilege manifests-such as racial privilege as compared to class privilege. Also relevant are Crenshaw's (1991) and Collins's (2002) notions of intersectionality: the idea that for people whose positionality includes multiple marginalized groups, such as being differently abled and being a person of color, the issues faced as a person of color are never completely separate from those faced because of ableness (Pyles, 2013, p. 13, 166).

\section{Power}

If privilege is positionality that confers unearned advantages, it follows that privilege by definition involves relative amounts of power. And relative is an important modifier, indicating that occupying a position of privilege means not just having power but having more power than certain other 
groups of people have. We see connections here to Foucault's (1982) notions of power, identity, and knowledge as intertwined. Foucault sought to learn about power by examining struggles against power, finding three kinds of struggles: against domination (power of one group over another), against exploitation (separation of people from what they produce), and against subjectivity (categorization of people and the positioning of them as dependent upon others' control; 1982, pp. 781-782). This third struggle, he claimed, is becoming increasingly important, "even though the struggles against forms of domination and exploitation have not disappeared. Quite the contrary" (p. 782). We agree.

As central tenets of inclusive work, positionality, privilege, and power reflect the amalgam of efforts we report in our antenarrative; each area or focus of study calls into question positionality, privilege, and power in their articulations of technical communication. We frame these tenets as a heuristic that can help scholars continue producing a more inclusive field, drawing together the field through these macroconcepts so as to enable microlevel studies and change. In this way, the 3Ps focus methodologically, helping us decide how to proceed. So what does this approach look like in action? We offer an extended example to demonstrate the ways this antenarrative and its accompanying heuristic can ground and guide future work.

\section{Researching with the 3Ps}

We suggest that the 3Ps, as an extension of this inclusive antenarrative, can and should guide research as a methodological approach. For us, this means planning our projects with the understanding that they can and should build toward inclusivity and examine positionality, privilege, and power as recursive and central pieces of our studies. At present, Moore is developing a study of transportation planning in Chile, where the government is launching a major overhaul of the transport system. At present, the research questions on this project are broad: How do planners and engineers communicate transportation-planning projects to the public? In what ways do citizens engage with the projects and participate in the planning? How does the planning affect or shape citizen visions of their community? In designing this research, we see that placing the 3Ps at the center of the project shifts it in important ways.

Positionalilty: Focuses on reflexivity and building relationships, builds from the assumption that subjectivity and, particularly, oppression are intersectional.

For the Chilean transport project, this means that the researcher initiates the project first through building relationships, understanding that her own position limits what claims can be made and what kinds of access she will or should have. In other words, positionality is implemented as a self-reflexive measure in the research study. Among other things, for example, the researcher can interrogate her own positionality by acknowledging that her purpose for involvement in the project may differ greatly from that of other stakeholders. The research questions, then, are flexible and emergent as the researcher works to build relationships with stakeholders, understand local needs, and develop the project in concert with the local community. This approach echoes Smith's (1999) and Abgoka's (2014) approaches to decolonial methodologies that eschew the colonial practices that often motivate research in the Western academy.

Privilege: Seeks to understand the way unequal opportunity shapes or reflects both the questions asked and the results of the study.

Transportation can be understood primarily a techno-material infrastructure, constructed by engineers given the safety, risk, and material research that dominates the sciences. In Chile, as in other places, however, analyzing transportation planning as a sociotechnical system that contributes to privilege shifts and shapes the project in new ways. Although the researcher could investigate the efficiency enabled or compromised by the new transport system, the pursuit of inclusion and social justice reframes the investigation as a question of whose needs are privileged in the project. The researcher may also examine concerns such as whose voices 
are heard and who can contribute to project decisions. Further, the researcher can ask how her research may include more voices and multiple perspectives, acknowledging that her work, like all work, will privilege some perspectives and information over others.

Power: Examines the ways power constructs enable particular arguments. Investigates power as part of the privilege/positionality relationship. Considers issues of agency.

In Chile, decisions about transportation reflect a power structure that could-but should not-be implicitly accepted as a background for the artifacts, communications, and problems of transportation planning. In considering power as a central tenet of inclusive work, then, the researcher considers how power functions as a part of the decision-making construct and-in moving toward social justice-focuses on those who might be dominated, exploited, or subjected to others' visions of their lives and, specifically, the role of transportation in their lives. More than adopting de Certeau's (1984) strategies or tactics, the researcher seeks to understand the ways that transportation planning and the research project itself is imbued with questions of agency, power, and opportunities to respond to the inequities that the project reveals.

As illustrated, the 3Ps offer practical value for informing inclusive TPC scholarship. In Table 1 we present a heuristic based on these three tenets of inclusive work to guide the field moving forward:

As illustrated in the heuristic, the 3Ps can be used in purposeful and actionable ways to support more inclusive TPC research. Researchers can first identify how each of the 3Ps are enacted in their research through an examination of the working definition. Then, researchers can narrow their focus by interrogating how each of the 3Ps can be considered as specifically applying to research. Finally, researchers can use the guiding questions to intentionally move their research toward inclusion.

Table 1. Tenets of inclusive work.

\begin{tabular}{|c|c|c|c|}
\hline & Positionality & Privilege & Power \\
\hline $\begin{array}{r}\text { Foundational } \\
\text { description }\end{array}$ & $\begin{array}{l}\text { Understanding identity as } \\
\text { complex, dynamic, and } \\
\text { contextual. }\end{array}$ & $\begin{array}{l}\text { Positionality that confers } \\
\text { unearned advantages. }\end{array}$ & $\begin{array}{l}\text { Distributed relative to privilege } \\
\text { and positionality. Considers } \\
\text { abuses such as domination, } \\
\text { exploitation, and subjectivity. }\end{array}$ \\
\hline $\begin{array}{l}\text { Applied } \\
\text { considerations for } \\
\text { inclusive research }\end{array}$ & $\begin{array}{l}\text { Ways that the researcher's and } \\
\text { others' subjectivity is shaped by } \\
\text { and shapes the research project. }\end{array}$ & $\begin{array}{l}\text { Ways that unearned advantages } \\
\text { and disadvantages shape } \\
\text { researchers' and others' } \\
\text { assumptions and experiences } \\
\text { relevant to the research project. }\end{array}$ & $\begin{array}{l}\text { Ways that power is wielded in } \\
\text { the research project. }\end{array}$ \\
\hline $\begin{array}{l}\text { Reflection questions } \\
\text { to inform and } \\
\text { guide inclusive } \\
\text { research }\end{array}$ & $\begin{array}{l}\text { - How do aspects of my identity } \\
\text { shape the way I think about } \\
\text { research: what it is? what it's } \\
\text { for? who does it? how to do it } \\
\text { well? } \\
\text { - In what ways do aspects of } \\
\text { participants' identities inform } \\
\text { their perspectives of the } \\
\text { research phenomena and the } \\
\text { processes used to study it? }\end{array}$ & $\begin{array}{l}\text { What unearned advantages } \\
\text { are at play in interactions } \\
\text { among stakeholders (including } \\
\text { myself) in the research } \\
\text { environment? } \\
\text { - What disadvantages exist as a } \\
\text { direct result of stakeholders' } \\
\text { positionality (including my } \\
\text { own)? } \\
\text { - How do I acknowledge a mul- } \\
\text { tiplicity of perspectives? }\end{array}$ & $\begin{array}{l}\text { - What potential harms (e.g., } \\
\text { blind spots, assumptions, } \\
\text { discourtesies, offenses) } \\
\text { might the unquestioned, } \\
\text { unacknowledged wielding } \\
\text { of my power cause? } \\
\text { - Who is silenced in my } \\
\text { research? } \\
\text { - Who is given voice in my } \\
\text { research? } \\
\text { - How do I promote agency in } \\
\text { my research? } \\
\text { - How do I act as an advocate } \\
\text { in my research? }\end{array}$ \\
\hline
\end{tabular}




\section{Conclusion: Making possible new futures}

Antenarratives are generative, productive, and forward thinking. Due to these qualities, antenarratives allow us to embrace and pursue inclusion in TPC, though acknowledging that a more pointed advocacy is necessary as we gather and extend inclusive threads. The antenarrative presented in this article seeks to make existing inclusive scholarship more visible and to enable future scholars to take up the work of inclusive technical communication with an eye toward social justice. To facilitate action informed by antenarrative's prospective sense making, we present a practical heuristic that scaffolds ways TPC researchers can consider how positionality, privilege, and power are articulated and inscribed in research projects. Finally, we call for other scholars who see possibilities in an inclusive approach to TPC to take up our call, equipped with a history that reflects the field's extensive and multithreaded tradition of making room for traditionally marginalized and excluded perspectives, populations, and positions.

Although we tie these threads together, not all scholars can or should include every thread in every work: Indeed, we see a need for the term inclusion as a means of facilitating individuals in purposefully and carefully pursuing research agendas that focus on one particular thread without the threat of chastisement because of their narrow scope. We suggest, but do not prescribe, social justice approaches-which need more definition, more methodological discussion, more clear articulations-as one way forward. Ultimately, we seek a field that is stalwart in its pursuit of social justice and inclusion. In concluding this antenarrative, then, we pick up the inclusive threads and pull them along a social justice trajectory. This, we admit, is our own trajectory: one way forward based upon the lineage of inclusive TPC. As illustrated in the preceding threads, TPC scholars have long written about and researched strategies for developing more inclusive approaches to technical communication. These approaches emphasize, demonstrate, and support our field's attempts to collectively advocate for social justice as a central objective of more inclusive research and pedagogy.

But there is still more work to do. In crafting this antenarrative, we risk suggesting that plenty of work has been done. We assure you, that is not true. Scholars working at the boundaries of social justice and TPC are bombarded with pushback as to why a focus on inclusion matters in TPC research. These scholars are often called to defend their work as viable technical communication research. Thus, we write this article to provide a starting point for TPC researchers seeking to more critically consider inclusion. We also write this article in defense of those researchers already doing the complex, messy, but often invisible work of addressing inclusion. We need more scholars who argue that inclusion is key to the work that we do in TPC. Specifically, we call for more work surrounding the role of women, feminism, and gender in the field of technical communication; we call for increasing attention to the ableist foundations of technical communication that imbue it with normalcy that can be exclusionary; we call for the integration of theories of race and ethnicity, and, as importantly, the experiences of people of color as we work to diversify the field; following Faris (2015), we call for any work at all that acknowledges the need to queer technical communication and resist the binaries that continue to dominate the field. In short, we seek any and all TPC research and pedagogy that embraces perspectives and knowledges that do not necessarily assume an anticultural, Westernized, heteronormative, and patriarchal positionality.

In crafting our antenarrative, we suggest that social justice scholarship might provoke other now-silent (or silenced) scholars to develop research agendas that reach toward the goal of inclusion. We also call for other ways forward, other goals, and other approaches and methodologies for social action. We hope to move beyond critique and, as Porter, Sullivan, Blythe, Grabill, and Miles (2000) suggest, create and draw together other seemingly disparate narratives to tell a different, more inclusive and more just story of what our field can and, we hope, will be. 


\section{Note}

1. As the threads of our antenarrative illustrate, technical communicators have been critically engaging with inclusivity in stops and starts. It has been happening, quietly (and sometimes nearly invisibly) for quite some time. We seek inclusion as the end goal over diversity for a number of reasons.

- Inclusion, as a term itself, moves beyond "mere" diversity. We do, of course, support the move to diversify the field in philosophical and pragmatic ways. However, the term diversity comes with baggage (Savage \& Mattson, 2011), and little if any evidence supports the notion that merely increasing the diversity of an organization, campus, or discipline changes the culture of the institution.

- A focus on inclusivity prompts infrastructural correctives, drawing attention to practices, policies, and processes for decision making at the macro- and mezzolevel. Inclusion is rooted in the action born out of critical work to become and encourage social justice (i.e., to redress inequities and acknowledge harm). Inclusivity allows scholars to occupy a deliberate positionality that privileges action and social change without being prescriptive and relying on only passive representation.

- The focus on inclusion allows scholars to draw together across macrolevel concerns and resources. Rather than ask, "Why aren't you doing [insert-the-thing-I-do]?" inclusivity is an attitude of both/and that invites all scholars to work toward less exclusionary practices in TPC.

- Most importantly, inclusivity allows scholars to engage with the intersectional notions that are central to our understanding of social justice and change work: drawing upon what Freire (1996) called "praxis," i.e., an essential, not-to-be-separated pairing of reflection and action (p. 68).

In short, we suggest that inclusion provides a series of ideals and action-oriented practices that, in keeping with our antenarrative, provides a less exclusive and more just approach (and future) for TPC.

\section{Acknowledgment}

The authors' names are listed alphabetical order, and the manuscript was fully collaborative.

\section{Notes on contributors}

Natasha N. Jones's research interests include activism, social justice, narrative, and rhetoric in technical communication and technical communication pedagogy. Her work has been published in Technical Communication Quarterly, the Journal of Technical Writing and Communication, and Rhetoric, Professional Communication, and Globalization. She is a graduate of the University of Washington's Human Centered Design \& Engineering Department (2012) and the winner of the 2014 Conference on College Composition and Communication (CCCC) Outstanding Dissertation in Technical Communication Award. She is the current chair of the Council for Programs in Technical and Scientific Communication's (CPTSC) Diversity Committee.

Kristen R. Moore works at the intersection of public rhetoric and technical communication, focusing specifically on the ways diverse communities might be served by critical theories, inclusive rhetorics, and activist scholarship. Of particular interest for Dr. Moore's research is the ways that seemingly mundane institutional infrastructure might serve as a sight of institutional and social change. Dr. Moore serves on the Diversity Committee for the Council for Programs in Technical and Scientific Communication and works on the Women in Tech Comm Initiative for the Association of Teachers of Technical Writing.

Rebecca Walton is an assistant professor at Utah State University. Her research interests in technical and professional communication include social justice, human dignity and human rights, and qualitative methods for cross-cultural research. Much of her research investigates how people in resource-constrained environments such as in the Global South and humanitarian organizations create, access, share, evaluate, and use information to meet their personal and professional goals. Primarily a field researcher, she has collaborated with organizations such as the Red Cross, Mercy Corps, and World Vision to conduct research in countries including Uganda, Kyrgyzstan, and Bolivia. Her work has appeared in Technical Communication Quarterly; Journal of Business and Technical Communication; Journal of Rhetoric, Professional Communication, and Globalization; and Information Technologies and International Development, as well as other journals and edited collections.

\section{References}

Agboka, G. Y. (2013). Participatory localization: A social justice approach to navigating unenfranchised/disenfranchised cultural sites. Technical Communication Quarterly, 22(1), 28-49. doi:10.1080/10572252.2013.730966 
Agboka, G. Y. (2014). Decolonial methodologies: Social justice perspectives in intercultural technical communication research. Journal of Technical Writing and Communication, 44(3), 297-327. doi:10.2190/TW.44.3.e

Alcoff, L. (1988). Cultural feminism versus post-structuralism: The identity crisis in feminist theory. Signs: Journal of Women in Culture and Society, 13(3), 405-436. doi:10.1086/494426

Banks, A. J. (2006). Race, rhetoric, and technology: Searching for higher ground. New York, NY: Routledge.

Barton, B. F., \& Barton, M. S. (1993). Ideology and the map: Toward a postmodern visual design practice. In N. R. Blyler \& C. Thralls (Eds.), Professional communication: The social perspective (pp. 49-78). Newbury Park, CA: Sage.

Beamer, L. (1992). Learning intercultural communication competence. Journal of Business Communication, 29(3), 285-303. doi:10.1177/002194369202900306

Black, L. L., \& Stone, D. (2005). Expanding the definition of privilege: The concept of social privilege. Journal of Multicultural Counseling and Development, 33(4), 243-255. doi:10.1002/j.2161-1912.2005.tb00020.x

Blackmon, S. (2004). Which came first? On minority recruitment and retention in the academy. CPTSC Proceedings, 1-3.

Blyler, N. R. (1995). Research as ideology in professional communication. Technical Communication Quarterly, 4(3), 285-313. doi:10.1080/10572259509364602

Boje, D., Rosile, G. A., \& Gardner, C. L. (2004). Antenarratives, narratives and anaemic stories. Presented at the All Academy Symposium "Actionable Knowledge as the Power to Narrate" Meeting of the Academy of Management, New Orleans, LA.

Boje, D. M. (2001). Narrative methods for organizational \& communication research. London,England: Sage.

Boje, D. M. (2008). Storytelling organizations. London, England: Sage.

Bosley, D. S. (1994). Feminist theory, audience analysis, and verbal and visual representation in a technical communication writing task. Technical Communication Quarterly, 3(3), 293-307. doi:10.1080/10572259409364573

Brasseur, L. (2005). Florence Nightingale's visual rhetoric in the rose diagrams. Technical Communication Quarterly, 14(2), 161-182. doi:10.1207/s15427625tcq1402_3

Britt, E. C. (2001). Conceiving normalcy: Rhetoric, law, and the double binds of infertility. Tuscaloosa, AL: University of Alabama Press.

Cardon, P. W. (2008). A critique of Hall's contexting model: A meta-analysis of literature on intercultural business and technical communication. Journal of Business and Technical Communication, 22(4), 399-428. doi:10.1177/ 1050651908320361

Carter, J., \& Markel, M. (2001). Web accessibility for people with disabilities: An introduction for web developers. IEEE Transactions on Professional Communication, 44(4), 225-233. doi:10.1109/47.968105

Collins, P. H. (2002). Black feminist thought: Knowledge, consciousness, and the politics of empowerment. New York, NY: Routledge.

Connors, R. J. (1982). The rise of technical writing instruction in America. Journal of Technical Writing and Communication, 12(4), 329-352. doi:10.2190/793K-X49Q-XG7M-C1ED

Coppola, N., \& Karis, B. (Eds.). (2000). Technical communication, deliberative rhetoric, and environmental discourse: Connections and directions. Greenwood Publishing Group.

Crenshaw, K. (1991). Mapping the margins: Intersectionality, identity politics, and violence against women of color. Stanford Law Review, 43(6), 1241-1299. doi:10.2307/1229039

Cushman, E. (2015, April 25). Live, work as a team. Retrieved from http://www.ellencushman.com/social-change/ditsaligo-itsehesdi-live-work-as-a-team

de Certeau, M. (1984). The practice of everyday life. Berkeley, CA: University of California Press.

Ding, H. (2013). Transcultural risk communication and viral discourses: Grassroots movements to manage global risks of H1N1 flu pandemic. Technical Communication Quarterly, 22(2), 126-149. doi:10.1080/10572252.2013.746628

Ding, H., \& Savage, G. (2013). Guest editors' introduction: New directions in intercultural professional communication. Technical Communication Quarterly, 22(1), 1-9. doi:10.1080/10572252.2013.735634

Dobrin, D. N. (1983). What's technical about technical writing? In P. V. Anderson, R. J. Brockmann, \& C. R. Miller (Eds.), New essays in technical and scientific communication: Research, theory, practice (pp. 227-250). Amityville, NY: Baywood.

Dubinsky, J. M. (2004). Teaching technical communication: Critical issues for the classroom. Boston, MA: Bedford/St. Martin's.

Dura, L., Singhal, A., \& Elias, E. (2013). Minga Perú's strategy for social change in the Peruvian Amazon: A rhetorical model for participatory, intercultural practice to advance human rights. Rhetoric, Professional Communication, and Globalization, 4(1), 33-54.

Durack, K. (1997). Gender, technology and the history of technical communication. Technical Communication Quarterly, 6(3), 249-260. doi:10.1207/s15427625tcq0603_2

Eble, M. F., \& Gaillet, L. L. (2004). Educating "community intellectuals": Rhetoric, moral philosophy, and civic engagement. Technical Communication Quarterly, 13(3), 341-354. doi:10.1207/s15427625tcq1303_7

Evia, C., \& Patriarca, A. (2012). Beyond compliance: Participatory translation of safety communication for Latino construction workers. Journal of Business and Technical Communication, 26(3), 340-367. doi:10.1177/1050651912439697 
Faris, M. (2015, March). Addressing normativity in technical communication: Putting technical communication in conversation with queer theory. Paper presented at the Conference for the Association of Teachers of Technical Communication, Tampa, FL.

Foucault, M. (1982). The subject and power. Critical Inquiry, 8(4), 777-795. doi:10.1086/448181

Freire, P. (1996). Pedagogy of the oppressed. New York, NY: Continuum.

Friess, E. (2010). The sword of data: Does human-centered design fulfill its rhetorical responsibility? Design Issues, 26 (3), 40-50. doi:10.1162/DESI_a_00028

Frost, E. (2014). Apparent feminist pedagogies: Interrogating technical rhetorics at Illinois State University. Programmatic Perspectives, 6(1), 110-131.

Frost, E. (2015). Apparent feminist pedagogies: Embodying feminist pedagogical practices at East Carolina University. Programmatic Perspectives, 7(2), 251-276.

Getto, G. (2014). Designing for engagement: Intercultural communication and/as participatory design. Rhetoric, Professional Communication, and Globalization, 5(1), 44-66.

Grabill, J. T. (2001). Community literacy programs and the politics of change. Albany, NY: SUNY Press.

Grabill, J. T. (2003). The written city: Urban planning, computer networks, and civic literacies. In B. McComiskey \& C. Ryan (Eds.), City comp: Identities, spaces, practices (pp. 128-141). New York, NY: SUNY Press.

Grabill, J. T., \& Simmons, W. M. (1998). Toward a critical rhetoric of risk communication: Producing citizens and the role of technical communicators. Technical Communication Quarterly, 7(4), 415-441. doi:10.1080/ 10572259809364640

Gurak, L., \& Bayer, N. (2004). Making gender visible: Extending feminist critiques of technology to technical communication. In J. M. Dubinsky (Ed.), Teaching technical communication (pp. 446-457). Boston, MA: Bedford/St. Martin's.

Gutsell, M., \& Hulgin, K. (2013). Supercrips don't fly: Technical communication to support ordinary lives of people with disabilities. In L. Meloncon (Ed.), Rhetorical accessability: At the intersection of technical communication and disability studies (pp. 84-94). Amityville, NY: Baywood.

Haas, A. M. (2012). Race, rhetoric, and technology: A case study of decolonial technical communication theory, methodology, and pedagogy. Journal of Business and Technical Communication, 26(3), 277-310. doi:10.1177/ 1050651912439539

Hannah, M. A. (2010). Legal literacy: Coproducing the law in technical communication. Technical Communication Quarterly, 20(1), 5-24. doi:10.1080/10572252.2011.528343

Herndl, C. G. (1993). Teaching discourse and reproducing culture: A critique of research and pedagogy in professional and non-academic writing. College Composition and Communication, 44(3), 349-363. doi:10.2307/358988

Hunsinger, R. P. (2006). Culture and cultural identity in intercultural technical communication. Technical Communication Quarterly, 15(1), 31-48. doi:10.1207/s15427625tcq1501_4

Jarrett, C., Redish, J., \& Summers, K. (2013). Designing for people who do not read easily. In L. K. Meloncon (Ed.), Rhetorical accessability (pp. 39-66). Amityville, NY: Baywood.

Johnson, R. R. (1998). User-centered technology: A rhetorical theory for computers and other mundane artifacts. Albany, NY: State University of New York Press.

Johnson-Eilola, J. (1996). Relocating the value of work: Technical communication in a post-industrial age. Technical Communication Quarterly, 5(3), 245-270. doi:10.1207/s15427625tcq0503_1

Johnson-Eilola, J., \& Selber, S. A. (Eds.). (2013). Solving problems in technical communication. Chicago, IL: University of Chicago Press.

Jones, N. N. (2014). The importance of ethnographic research in activist networks. In M. F. Williams \& O. Pimentel (Eds.), Communicating race, ethnicity, and identity in technical communication (pp. 46-62). Amityville, NY: Baywood.

Jones, N. N. (2016a). Narrative inquiry in human centered design: Examining silence and voice to promote social justice in design scenarios. Journal of Technical Writing and Communication, 46(1), 2016. doi:10.1177/ 0047281616653489

Jones, N. N. (2016b). The technical communicator as advocate: Integrating a social justice approach in technical communication. Journal of Technical Writing and Communication, 46(3), 342-361. doi:10.1177/0047281616639472

Jones, N. N., \& Walton, R. (forthcoming). Using narratives to foster critical thinking about diversity and social justice. In M. Eble \& A. Haas (Eds.), Integrating theoretical frameworks for teaching technical communication.

Katz, S. B. (1992). The ethic of expediency: Classical rhetoric, technology, and the Holocaust. College English, 54(3), 255-275. doi: $10.2307 / 378062$

Kelly, K. (2014). Americans' changing perceptions of Indian cultural identity: An analysis of Indian call centers. In M. F. Williams \& O. Pimentel (Eds.), Communicating race, ethnicity, and identity in technical communication (pp. 135-152). Amityville, NY: Baywood.

Koerber, A. (2000). Toward a feminist rhetoric of technology. Journal of Business and Technical Communication, 14(1), 58-73. doi:10.1177/105065190001400103

Koerber, A. (2013). Breast or bottle? Contemporary controversies in infant-feeding policy and practice. Columbia, SC: University of South Carolina Press. 
Kossek, E. E., \& Zonia, S. C. (1994). The effects of race and ethnicity on perceptions of human resource policies and climate regarding diversity. Journal of Business and Technical Communication, 8(3), 319-334. doi:10.1177/ 1050651994008003004

Kynell, T., Tebeaux, E., \& Allen, J. (1997). Guest editors' column. Technical Communication Quarterly, 6(3), $245-247$. doi:10.1207/s15427625tcq0603_1

LaDuc, L., \& Goldrick-Jones, A. (1994). The critical eye, the gendered lens, and "situated" insights: Feminist contributions to professional communication. Technical Communication Quarterly, 3(3), 245-256. doi:10.1080/ 10572259409364570

Lay, M. M. (1991). Feminist theory and the redefinition of technical communication. Journal of Business and Technical Communication, 5(4), 348-370. doi:10.1177/1050651991005004002

Limaye, M. R. (1994). Responding to work-force diversity conceptualization and search for paradigms. Journal of Business and Technical Communication, 8(3), 353-372. doi:10.1177/1050651994008003007

Lippincott, G. (2003). Rhetorical chemistry: Negotiating gendered audiences in nineteenth-century nutrition studies. Journal of Business and Technical Communication, 17(1), 10-49. doi:10.1177/1050651902238544

Matsuda, P. K., \& Atkinson, D. (2008). A conversation on contrastive rhetoric. In U. Connor, E. Nagelhout, \& W. Rozycki (Eds.), Contrastive rhetoric: Reaching to intercultural rhetoric (pp. 277-298). Amsterdam, The Netherlands: Benjamins.

Medina, C. (2014). Tweeting collaborative identity: Race, ICTs, and performing Latinidad. In M. F. Williams \& O. Pimentel (Eds.), Communicating race, ethnicity, and identity in technical communication (pp. 63-86). Amityville, NY: Baywood.

Miller, C. R. (1979). A humanistic rationale for technical writing. College English, 40(6), 610-617. doi:10.2307/375964

Moore, K. (2013). Exposing hidden relations: Storytelling, pedagogy, and the study of policy. Journal of Technical Writing and Communication, 43(1), 63-78. doi:10.2190/TW.43.1.d

Moore, K. (forthcoming). A resistant pedagogy: Black feminist theory as a framework community-based teaching. In M. Eble \& A. Haas (Eds.), Integrating theoretical frameworks for teaching technical communication.

Moore, K. R., \& Elliott, T. J. (2016). From participatory design to a listening infrastructure: A case of urban planning and participation. Journal of Business and Technical Communication, 30(1), 59-84. doi:10.1177/1050651915602294

Mukavetz, A. M. R. (2014). Towards a cultural rhetorics maethodology: Making research matter with multi-generational women from the Little Traverse Bay Band. Rhetoric, Professional Communication, and Globalization, 5(1), $108-125$.

Ornatowski, C. M. (1992). Between efficiency and politics rhetoric and ethics in technical writing. Technical Communication Quarterly, 1(1), 91-103. doi:10.1080/10572259209359493

Ornatowski, C. M., \& Bekins, L. K. (2004). What's civic about technical communication? Technical communication and the rhetoric of "community. Technical Communication Quarterly, 13(3), 251-269. doi:10.1207/s15427625tcq1303_2

Oswal, S. K., \& Hewett, B. (2013). Accessibility challenges for visually impaired students and their online writing instructors.

Oswal, S. K., \& Meloncon, L. (2014). Paying attention to accessibility when designing online courses in technical and professional communication. Journal of Business and Technical Communication, 28(3), 271-300. doi:10.1177/ 1050651914524780

Palmeri, J. (2006). Disability studies, cultural analysis, and the critical practice of technical communication pedagogy. Technical Communication Quarterly, 15(1), 49-65. doi:10.1207/s15427625tcq1501_5

Paretti, M. C. (2003). Managing nature/empowering decision-makers: A case study of forest management plans. Technical Communication Quarterly, 12(4), 439-459. doi:10.1207/s15427625tcq1204_6

Pass, E. (2013). Accessibility and the web design student. In L. Meloncon (Ed.), Rhetorical accessability: At the intersection of technical communication and disability studies (pp. 115-134). Amityville, NY: Baywood.

Pimentel, C., \& Balzhiser, D. (2012). The double occupancy of Hispanics: Counting race and ethnicity in the US census. Journal of Business and Technical Communication, 26(3), 311-339. doi:10.1177/1050651912439696

Porter, J. E., Sullivan, P., Blythe, S., Grabill, J. T., \& Miles, L. (2000). Institutional critique: A rhetorical methodology for change. College Composition and Communication, 51(4), 610-642. doi:10.2307/358914

Price, R. J., Walton, R., \& Petersen, M. (2014). Methodological journey: Lessons learned from a student-led intercultural pilot study. Rhetoric, Professional Communication, and Globalization, 5(1), 90-107.

Pyles, L. (2013). Progressive community organizing: A critical approach for a globalizing world. New York, NY: Routledge.

Redish, J. (2010). Technical communication and usability: Intertwined strands and mutual influences. IEEE Transactions on Professional Communication, 53(3), 191-201. doi:10.1109/TPC.2010.2052861

Redish, J. G., \& Barnum, C. (2011). Overlap, influence, intertwining: The interplay of UX and technical communication. Journal of Usability Studies, 6(3), 90-101.

Richardson, F. (2014). The eugenics agenda: Deliberative rhetoric and therapeutic discourse of hate. In M. F. Williams \& O. Pimentel (Eds.), Communicating race, ethnicity, and identity in technical communication (pp. 7-22). Amityville, NY: Baywood.

Rude, C. D. (2009). Mapping the research questions in technical communication. Journal of Business and Technical Communication, 23(2), 174-215. doi:10.1177/1050651908329562 
Salvo, M. J. (2001). Ethics of engagement: User-centered design and rhetorical methodology. Technical Communication Quarterly, 10(3), 273-290. doi:10.1207/s15427625tcq1003_3

Sauer, B. A. (1993). Sense and sensibility in technical documentation: How feminist interpretation strategies can save lives in the nation's mines. Journal of Business and Technical Communication, 7(1), 63-83. doi:10.1177/ 1050651993007001004

Savage, G., \& Mattson, K. (2011). Perceptions of racial and ethnic diversity in technical communication programs. Programmatic Perspectives, 3(1), 5-57.

Scott, J. B. (1995). Sophistic ethics in the technical writing classroom: Teaching nomos, deliberation, and action. Technical Communication Quarterly, 4(2), 187-199. doi:10.1080/10572259509364596

Scott, J. B. (2003). Risky rhetoric: AIDS and the cultural practices of HIV Testing. Carbondale, IL: Southern Illinois University Press.

Scott, J. B. (2004). Rearticulating civic engagement through cultural studies and service-learning. Technical Communication Quarterly, 13(3), 289-306. doi:10.1207/s15427625tcq1303_4

Scott, J. B., Longo, B., \& Wills, K. V. (2006). Critical power tools: Technical communication and cultural studies. Albany, NY: SUNY Press.

Simmons, M. W., \& Grabill, J. T. (2007). Toward a civic rhetoric for technologically and scientifically complex places: Invention, performance, and participation. College Composition and Communication, 58(3), 419-448.

Simmons, W. M. (2007). Participation and power. Albany, NY: SUNY Press.

Simmons, W. M., \& Zoetewey, M. W. (2012). Productive usability: Fostering civic engagement and creating more useful online spaces for public deliberation. Technical Communication Quarterly, 21(3), 251-276. doi:10.1080/ 10572252.2012 .673953

Slack, J. D., Miller, D. J., \& Doak, J. (1993). The technical communicator as author: Meaning, power, authority. Journal of Business and Technical Communication, 7(1), 12-36. doi:10.1177/1050651993007001002

Smith, E. O., \& Thompson, I. (2002). Feminist theory in technical communication: Making knowledge claims visible. Journal of Business and Technical Communication, 16(4), 441-477. doi:10.1177/105065102236526

Smith, L. T. (1999). Decolonizing methodologies: Research and indigenous peoples. New York, NY: Zed Books.

Spinuzzi, C. (2005). The methodology of participatory design. Technical Communication, 52(2), $163-174$.

Spinuzzi, C. (2007). Texts of our institutional lives: Accessibility scans and institutional activity: An activity theory analysis. College English, 70(2), 189-201.

Starke-Meyerring, D. (2005). Meeting the challenges of globalization: A framework for global literacies in professional communication programs. Journal of Business and Technical Communication, 19(4), 468-499. doi:10.1177/ 1050651905278033

Sullivan, D. L. (1990). Political-ethical implications of defining technical communication as a practice. Journal of Advanced Composition, 10(2), 375-386.

Sullivan, P. (1989). Beyond a narrow conception of usability testing: A rationale for broadening usability. IEEE Transactions on Professional Communication, 32(4), 256-264. doi:10.1109/47.44537

Sullivan, P., \& Moore, K. (2013). Time talk: On small changes that enact infrastructural mentoring for undergraduate women in technical fields. Journal of Technical Writing and Communication, 43(3), 333-354. doi:10.2190/TW.43.3.f

Sullivan, P., \& Porter, J. E. (1998). On theory, practice, and method: Toward a heuristic research methodology for professional writing. In R. Spilka (Ed.), Writing in the workplace: New research perspectives (pp. 220-237). Carbondale, IL: Southern Illinois University Press.

Sun, H. (2012). Cross-cultural technology design: Creating culture-sensitive technology for local users. New York, NY: Oxford University Press.

Thatcher, B. (2006). Intercultural rhetoric, technology, and writing in Mexican maquilas. Technical Communication Quarterly, 15(3), 383-405. doi:10.1207/s15427625tcq1503_6

Thatcher, B. (2010). Editor introduction: Eight needed developments and eight critical contexts for global inquiry. Rhetoric, Professional Communication, and Globalization, 1(1), 1-34.

Thompson, I. (2004). Sex differences in technical communication: A perspective from social role theory. Journal of Technical Writing and Communication, 34(3), 217-232. doi:10.2190/PX6L-N9C7-0EAG-YA2X

Thompson, I., \& Smith, E. O. (2006). Women and feminism in technical communication: An update. Journal of Technical Writing and Communication, 36(2), 183-199. doi:10.2190/4JUC-8RAC-73H6-N57U

Victor, D. A. (1992). Intercultural business communication. New York, NY: Harper Collins.

Waddell, C. (1996). Saving the Great Lakes: Public participation in environmental policy. Green Culture: Environmental Rhetoric in Contemporary America, 141-165.

Walters, S. (2010). Toward an accessible pedagogy: Dis/ability, multimodality, and universal design in the technical communication classroom. Technical Communication Quarterly, 19(4), 427-454. doi:10.1080/10572252.2010.502090

Walton, R. (2013a). Bridges \& barriers to development: Communication modes, media, \& devices. Kairos: A Journal of Rhetoric, Technology, and Pedagogy, 17(3), . Retrieved from http://kairos.technorhetoric.net/17.3/topoi/walton/ index.html

Walton, R. (2013b). Stakeholder flux: Participation in technology-based international development projects. Journal of Business and Technical Communication, 27(4), 409-435. doi:10.1177/1050651913490940 
Walton, R. (2016). Supporting human dignity and human rights: A call to adopt the first principle of human-centered 875 design. Journal of Technical Writing and Communication, 46(4). doi:10.1177/0047281616653496

Williams, M. F. (2010). From black codes to recodification: Removing the veil from regulatory writing. Amityville, NY: Baywood.

Williams, M. F. (2013). A survey of emerging research: Debunking the fallacy of colorblind technical communication. Programmatic Perspectives, 5(1), 86-93.

Williams, M. F., \& Pimentel, O. (2012). Introduction: Race, ethnicity, and technical communication. Journal of Business and Technical Communication, 26(3), 271-276. doi:10.1177/1050651912439535

Williams, M. F., \& Pimentel, O. (2014). Communicating race, ethnicity, and identity in technical communication. Amityville, NY: Baywood.

Youngblood, S. A. (2013). Communicating web accessibility to the novice developer: From user experience to application. Journal of Business and Technical Communication, 27(2), 209-232. doi:10.1177/1050651912458924

Zachry, M., \& Thralls, C. (2007). Communicative practices in workplaces and the professions: Cultural perspectives on the regulation of discourse and organizations. Amityville, NY: Baywood.

Zdenek, S. (2007). "Just roll your mouse over me": Designing virtual women for customer service on the web. Technical Communication Quarterly, 16(4), 397-430. doi:10.1080/10572250701380766 